\title{
Welcome to Volume 2 of Future Drug Discovery
}

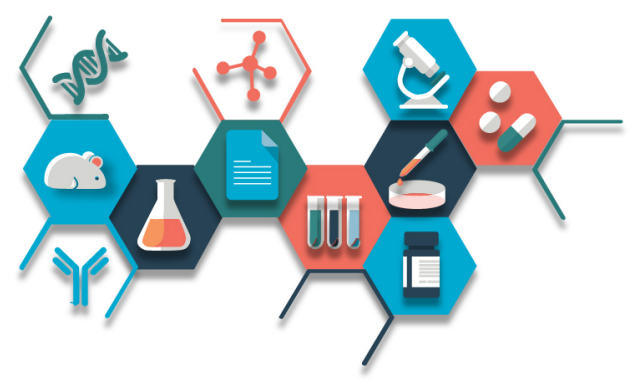

\author{
Francesca Lake*,1 iD \& Jennifer Straiton ${ }^{1}$ \\ ${ }^{1}$ Future Science Group, Unitec House, 2 Albert Place, London, N3 1QB, UK \\ *Author for correspondence: f.lake@future-science.com
}

\begin{abstract}
"This issue is focused around immuno-oncology and we have upcoming issues on drug-repurposing, anti-microbial resistance and computer-aided drug design."
\end{abstract}

First draft submitted: 28 November 2019; Accepted for publication: 28 November 2019; Published online: 5 February 2020

Happy New Year and welcome to Volume 2 of Future Drug Discovery. With 2019 seeing the launch of the journal, it was an exciting year for the Future Drug Discovery team and, in this Foreword, we discuss our highlights and look forward to what is coming in 2020.

\section{Content highlights from 2019}

Future Drug Discovery publishes quarterly issues and many of our issues carry a themed section surrounding a topic of high interest to the drug discovery community. In 2019, we covered the exciting topic of artificial intelligence (AI), which saw us speak with a number of experts to discuss AI concepts, such as the computational chemist, and discuss some of the challenges the AI field faces, including ethics and intellectual property [1]. Separate Editorials also saw R Lawrence (Cancer Research UK Manchester Institute, UK), E Begoli (Oak Ridge National Laboratory, TN, USA) and D Kusnezov (US Department of Energy, DC, USA) discuss their takes on the topic [2,3]. Begoli and Kusnezov summed the topic up nicely in their conclusion: "Clearly the process of drug discovery requires improvements, but the opportunities to do so with AI are manifest."

Various commentaries, research, review and opinion pieces were also published. One of our content highlights is a commentary from Zhang et al., which looks at the potential held by metal polyphenol nanonetworks for drug delivery [4]. This article has been read over 900 times and currently holds our most-cited spot. Our most-read article thus far is a research article by Kanna et al., which saw the team investigate whether their perlecan-targeted nanoparticles could improve drug delivery in triple-negative breast cancer [5].

We also published a series of interviews with people from various aspects of the drug discovery field discussing life in their areas, including experts from an independent consultancy, contract research organizations and a start-up in a science incubator. We look forward to continuing this series, as it provides an interesting look into the drug discovery careers landscape.

\section{Special issues in $\mathbf{2 0 2 0}$}

The year of 2020 will see us publish a plethora of both general and thematic content. This issue is focused around immuno-oncology and we have upcoming issues on drug-repurposing, anti-microbial resistance and computeraided drug design. If you would like to discuss ideas for any of these issues, please contact us via email.

\section{Maximizing discovery across the globe}

Future Drug Discovery utilizes a number of services to help support its researchers and maximize the visibility and impact of work. These include Publons (rewarding peer review), Altmetrics (tracking online discussion of articles, such as via social media or news outlets), Dimensions (tracking citations) and ScienceOpen (disseminating research widely and putting it into context). Download, Dimensions and Altmetrics statistics will be shown on article pages, meaning authors can track the success of their articles. At the time of writing (November 2019), our articles had seen nearly 11,000 full-text readers, which is excellent to see. These readers came from across the globe (Figure 1). 


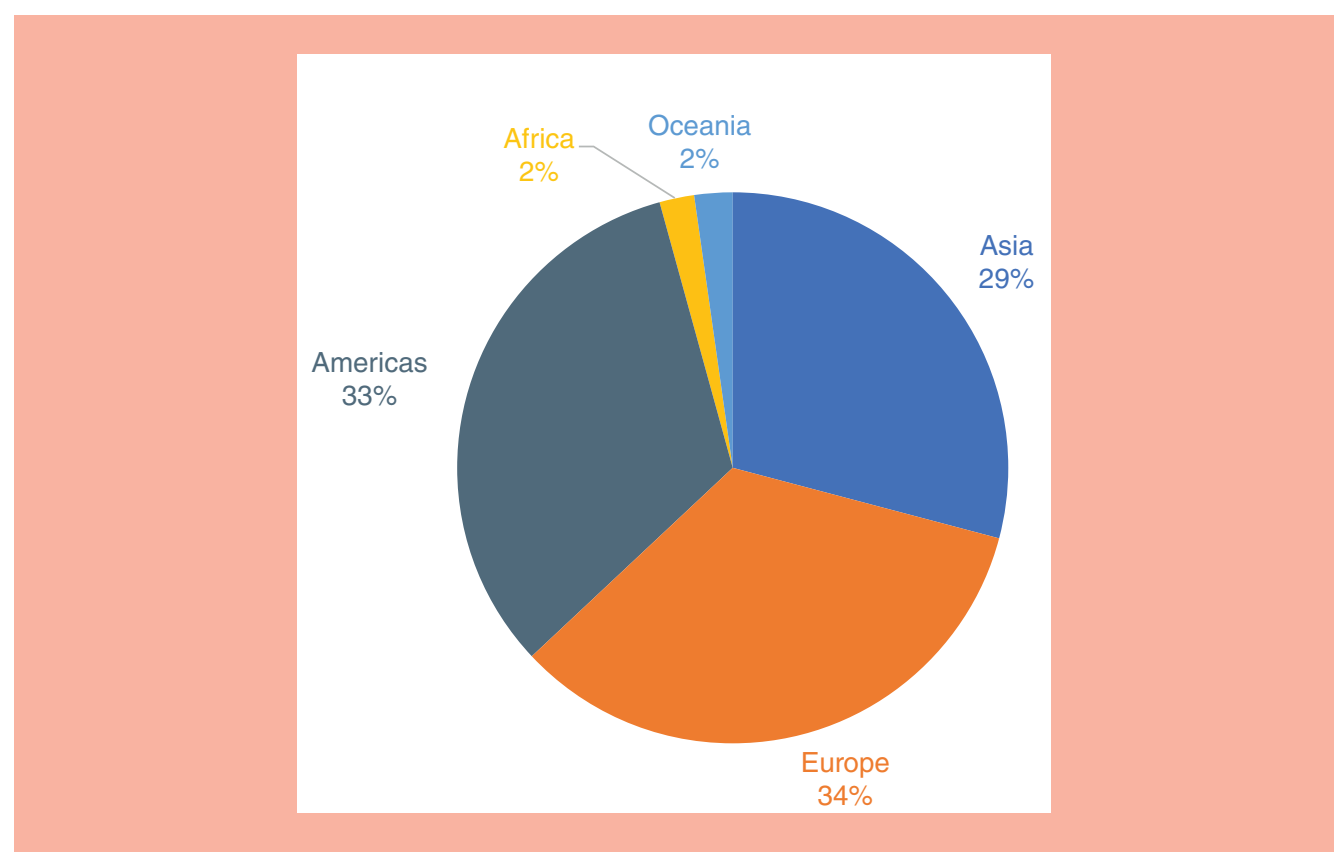

Figure 1. Future Drug Discovery readership 2019.

\section{Expanding the reach of our articles}

We are particularly proud of our partnership with RxNet [6], a free online resource that covers all aspects of pharma R\&D. Members of the site gain access to exclusive additional content that builds upon our open access articles, such as our peek behind the paper interview with author J Bajorath. In this interview, he gave further insight into his paper on a novel computational methodology to evaluate chemical optimization [7].

Working with the RxNet Editorial team, we were delighted to release the first edition of our Glossary of Drug Discovery last August [8]. Thanks to the help of our expert panel, we compiled a list of all the key terms used in drug discovery - from abbreviated new drug application to Z' factor - and provided handy definitions for your reference. The full glossary is available online and we also hand out physical copies of the book at relevant conferences, so watch out for our booths.

In addition, we continue to utilize the power of social media and share all new work on Twitter in order to insure it reaches the largest audience possible; if you do not already, we welcome you to follow us on Twitter (@fsdrugdiscovery).

\section{Conferences in $\mathbf{2 0 2 0}$}

Throughout 2019, we were lucky enough to attend multiple exciting conferences, including AAPS PharmSci 360 (TX, USA, 3-6 November 2019), ELRIG Drug Discovery (Liverpool, UK, 5-6 November 2019) and the 4th Medicinal Chemistry and Protein Degradation Summit (London, UK, 28-29 October 2019). It is always great to be able to meet our readers and authors and hear feedback on the journal.

If you have any suggestions for conferences in 2020 you would like to meet us at, please let us know. We will be attending various meetings in 2020 with members of the RxNet team, so be sure to look out for our booth and grab a copy of our glossary if you get the chance.

\section{Our Editorial Board \& contributors}

We are hugely thankful to our Editorial Board [9] for their help in creating Future Drug Discovery and their contributions thus far. Our board comprises experts from across the globe crossing both academia and industry and will be joined in 2020 by a panel of early career researchers who will work to help us ensure the journal is supporting researchers at all career levels. If you would be interested in joining our Early Career Panel, please get in touch; we would be delighted to hear your input. 
We would also like to thank all the authors and peer reviewers for their contributions in 2019, without whom Volume 1 would not have been possible - we look forward to working with them again in 2020.

\section{Conclusion}

Following a successful launch, we are excited to see the journal grow and gain recognition in the field over the coming years. Our plans for themed issues and a focus on early career research mean we have plenty to keep us busy in 2020, although we value any input you may have. If you have any ideas for the journal, be it an outline for an article or a theme for an issue, we would love to hear it, so please get in touch.

\section{Financial \& competing interests disclosure}

F Lake and J Straiton are employees of Future Science Ltd. The authors have no other relevant affiliations or financial involvement with any organization or entity with a financial interest in or financial conflict with the subject matter or materials discussed in the manuscript apart from those disclosed.

No writing assistance was utilized in the production of this manuscript.

\section{Open access}

This work is licensed under the Attribution-NonCommercial-NoDerivatives 4.0 Unported License. To view a copy of this license, visit http://creativecommons.org/licenses/by-nc-nd/4.0/

\section{References}

1. Future Science. Future Drug Discovery (2019). www.future-science.com/toc/fdd/1/2

2. Begoli E, Kusnezov D. Artificial intelligence's essential role in the process of drug discovery. Future Drug Discov. 1(2), FDD21 (2019).

3. Lawrence R. Now the future, we see our dreams: artificial intelligence in drug discovery. Future Drug Discov. 1(2), FDD22 (2019).

4. Zhang X, Parekh G, Guo B et al. Polyphenol and self-assembly: metal polyphenol nanonetwork for drug delivery and pharmaceutical applications. Future Drug Discov. 1(1), FDD7 (2019).

5. Khanna V, Kalscheuer S, Kirtane A, Zhang W, Panyam J. Perlecan-targeted nanoparticles for drug delivery to triple-negative breast cancer. Future Drug Discov. 1(1), FDD8 (2019).

6. RxNet (2020). http://www.rx-network.com

7. RxNet. A peek behind the paper: compound optimization monitor (COMO) for computational evaluation of lead optimization (2019). www.rx-network.com/users/242132-future-drug-discovery/posts/54812-a-peek-behind-the-paper-compound-optimization-monitorcomo-for-computational-evaluation-of-lead-optimization

8. Future Science. RxNet glossary of drug discovery (2019). www.future-science.com/doi/10.4155/fdd-2019-0101s

9. Future Science. Future Drug Discovery - editorial advisory board (2019). www.future-science.com/journals/fdd/editors 